\title{
Duet laparoscopic repair with knotless barbed sutures for treatment of perforated peptic ulcer: reality in general surgery with lacking of manpower
}

\author{
Dong-Wook Kim", Sanghyun Song", Ye Seob Jee \\ Department of Surgery, Dankook University College of Medicine, Chungnam, Republic of Korea \\ Contributions: (I) Conception and design: YS Jee; (II) Administrative support: YS Jee, S Song; (III) Provision of study materials or patients: DW Kim; \\ (IV) Collection and assembly of data: S Song, DW Kim; (V) Data analysis and interpretation: DW Kim; (VI) Manuscript writing: All authors; (VII) \\ Final approval of manuscript: All authors. \\ \#These authors contributed equally to this study. \\ Correspondence to: Ye Seob Jee, MD, PhD. Department of Surgery, Dankook University College of Medicine, 201 Manghyangro, Dongnam-gu, \\ Cheonan, 31116, Republic of Korea. Email: ysjee@dkuh.co.kr.
}

\begin{abstract}
Background: Perforated peptic ulcer (PPU) is a fatal complication of peptic ulcer disease, which requires emergency surgery. Laparoscopic repair is the widely accepted and effective method for the treatment of PPU. The aim of this study was to evaluate the safety and efficacy of duet laparoscopic repair of PPU with knotless barbed sutures.

Methods: From January 2013 to May 2019, 40 patients with PPU underwent laparoscopic primary repair and omentopexy at the Dankook University Hospital. The operative outcomes and complications of patients undergoing surgery using continuous suturing with absorbable knotless barbed sutures (group A, n=15) were compared with those undergoing surgery with conventional interrupted sutures (group B, n=25).

Results: The mean operative time was significantly shorter in group A than group B $(84.4 \pm 39.8 v s$. 104.2 $\pm 49.4 \mathrm{~min}, \mathrm{P}<0.001)$. There were no differences in other operative outcomes or postoperative complications (group A vs. group B, 20.0\% vs. 24.0\%, respectively; $\mathrm{P}=0.249$ ) between the two groups. The mean operation time spent for laparoscopic sutures and omentopexy was 22.7 minutes.

Conclusions: The findings of the current study, albeit performed retrospectively at a single institution, suggested that duet laparoscopic repair of PPU with knotless barbed sutures might be considered as an alternative option, especially in hospitals lacking manpower.
\end{abstract}

Keywords: Perforated peptic ulcer (PPU); laparoscopic repair; knotless barbed sutures

Submitted Apr 23, 2020. Accepted for publication Nov 15, 2020.

doi: 10.21037/atm-20-3496

View this article at: http://dx.doi.org/10.21037/atm-20-3496

\section{Introduction}

Perforated peptic ulcer (PPU) is a fatal complication of peptic ulcer disease, affecting $2-10 \%$ of patients, which requires emergency surgery (1). Although the incidence of peptic ulcer disease has been decreasing in recent decades due to eradication therapy for Helicobacter pylori and improvements in pharmacological therapies including $\mathrm{H} 2$ blockers and proton pump inhibitors, the incidence of PPU has largely remained unchanged $(2,3)$. PPU is the most important contributor to inpatient mortality in peptic ulcer disease due to accompanying peritonitis $(4,5)$. Surgery, which remains the standard of care for patients with PPU, has been simplified by primary repair of the perforation site and placement of a free omental patch $(6,7)$.

In gastroenterology, laparoscopic surgery has gained rapid and wide acceptance for the treatment of gastric cancer $(8,9)$. Recent studies demonstrated that advanced laparoscopic surgical approaches, such as reduced-port and 

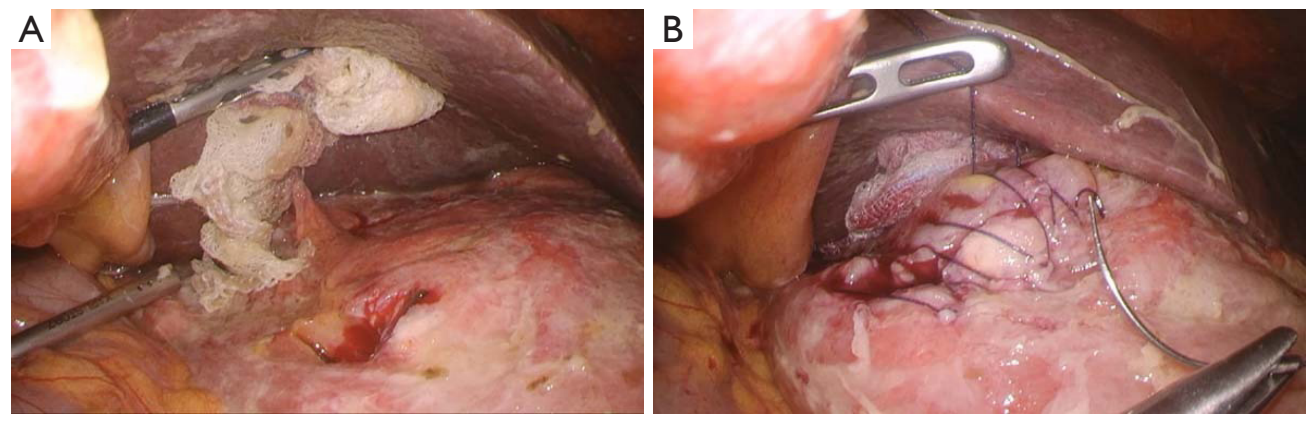

Figure 1 Photograph of operative procedures. (A) Detection of the ulcer perforation site. (B) Continuous suture using knotless absorbable barbed suture.

single-port surgeries, improved morbidity and mortality, reflecting their feasibility and safety (10-12). Although the advances in these techniques are due to the constant efforts of surgeons, the impact of developments in surgical instruments cannot be overlooked. One of the factors associated with improved outcomes with laparoscopic surgery is the knotless barbed suture, which features a needle fixed in one arm and a loop placed on the other side of the arm (13). At our institution, the knotless barbed suture has been utilized for surgical intervention in patients with PPU since 2017. In this study, we evaluated the safety and efficacy of duet laparoscopic repair of PPU using knotless barbed sutures.

We present the following article in accordance with the STROBE reporting checklist (available at http://dx.doi. org/10.21037/atm-20-3496).

\section{Methods}

\section{Patients and data}

A retrospective review was carried out between January 2013 and May 2019 to analyze the medical records of patients with PPU who underwent laparoscopic primary repair and omentopexy at the Dankook University Hospital. All patients were admitted to the emergency room with sudden onset of severe abdominal pain, and computed tomography scan confirmed the presence of pneumoperitoneum along the periduodenal area and evidence of peritonitis. Intravenous hydration and broadspectrum antibiotics were administered before surgery, and a nasogastric tube and Foley catheter were routinely inserted for drainage and monitoring.

Patients were classified into two groups according to the suture technique and material. The patients who underwent laparoscopic repair with continuous suture technique using knotless absorbable barbed sutures (3-0 V-Loc ${ }^{\mathrm{TM}}$; Covidien, Mansfield, MA, USA) comprised group A, whereas those who underwent the repair with interrupted simple sutures using absorbable braided sutures (3-0 Vicryl ${ }^{\mathrm{TM}}$; Ethicon, Cornelia, GA, USA) comprised group B. Duet surgery was performed in patients in group A without a first assistant, whereas conventional four- or five-port surgery was performed in patients in group B. In this study, patient demographics and surgical results as well as postoperative morbidity and mortality were compared between groups A and B. The institutional review board (IRB) of the Dankook University Hospital approved the protocol (IRB number; 201811021), and written informed consent was waived by the IRB. This study was performed according to the Helsinki Declaration (as revised in 2013).

\section{Operative procedures in group $A$}

To perform laparoscopy, two operator ports (5 and $12 \mathrm{~mm}$ ) were inserted in the patient's right side, with one additional umbilical port $(10 \mathrm{~mm})$. The liver was retracted outside the abdominal cavity using needle nylon sutures when the field of view was narrow. After identifying the perforation site, debridement of adjuvant tissues and biopsy of the ulcer margin were performed in feasible situations, to confirm potential malignancy. Laparoscopic repair was performed using continuous suture technique with knotless absorbable barbed sutures (Figure 1). Omentopexy was performed sequentially with the retained suture material. After irrigation of the peritoneal cavity, two closed suction drains were inserted along the pelvic cavity and right subhepatic space. Postoperative management and follow-up did not deviate significantly from those reported in other studies $(14,15)$. 
Table 1 Patients demographics and baseline characteristics $(n=40)$

\begin{tabular}{lccc}
\hline Characteristic & Group $A^{\dagger}(\mathrm{n}=15)$ & Group B $^{\ddagger}(\mathrm{n}=25)$ & $\mathrm{P}$ value \\
\hline Age (year) & $58.4 \pm 11.2$ & $56.4 \pm 13.5$ & 0.888 \\
Gender & & & 0.792 \\
Male & $11(73.3 \%)$ & $20(80.0 \%)$ & \\
Female & $4(26.7 \%)$ & $5(20.0 \%)$ & \\
BMI (kg/m $\left.{ }^{2}\right)$ & $22.7 \pm 3.1$ & $23.1 \pm 4.1$ & 0.548 \\
ASA score & & & \\
2 & $12(80.0 \%)$ & $21(84.0 \%)$ & 0.593 \\
$\geq 3$ & $3(20.0 \%)$ & $4(16.0 \%)$ & \\
Perforation site & & & 0.424 \\
Duodenum & $11(73.3 \%)$ & $19(76.0 \%)$ & \\
Stomach antrum & $4(26.7 \%)$ & $6(24.0 \%)$ & \\
\hline
\end{tabular}

${ }^{\dagger}$, continuous suture technique using knotless absorbable barbed sutures; ${ }^{\ddagger}$, interrupted simple sutures using absorbable braided sutures. BMI, body mass index; ASA, American Society of Anesthesiologists.

Table 2 Surgical results

\begin{tabular}{lccc}
\hline Variable & $\begin{array}{c}\text { Group } A^{\dagger} \\
(\mathrm{n}=15)\end{array}$ & $\begin{array}{c}\text { Group } B^{\ddagger} \\
(\mathrm{n}=25)\end{array}$ & P value \\
\hline Operative time (min) & $84.4 \pm 39.8$ & $104.2 \pm 49.4$ & $<0.001$ \\
Size of perforation site (cm) & $1.2 \pm 0.7$ & $1.1 \pm 0.6$ & 0.386 \\
Postoperative stay (day) & $8.5 \pm 6.4$ & $8.7 \pm 5.2$ & 0.748 \\
Days of drainage (day) & $4.5 \pm 2.4$ & $4.7 \pm 3.1$ & 0.421 \\
Day of diet resumption (day) & $3.3 \pm 1.5$ & $3.5 \pm 1.4$ & 0.241 \\
\hline
\end{tabular}

${ }^{\dagger}$, continuous suture technique using knotless absorbable barbed sutures; ${ }^{\ddagger}$, interrupted simple sutures using absorbable braided sutures.

\section{Statistical analysis}

Categorical data were assessed using the $\chi^{2}$ test or Fisher's exact test. In addition, Student's $t$-test or the MannWhitney $U$ test was used to assess continuous variables. A $\mathrm{P}<0.05$ was considered statistically significant. All statistical analyses were performed using the SPSS software package for Windows, version 22.0 (IBM, Chicago, IL, USA).

\section{Results}

In total, 40 patients (group $\mathrm{A} ; \mathrm{n}=15$, group $\mathrm{B} ; \mathrm{n}=25$ ) were
Table 3 Postoperative morbidity and mortality

\begin{tabular}{lccc}
\hline Variable & $\begin{array}{c}\text { Group A }^{\dagger}(\mathrm{n}=15) \\
\text { Group B } \\
(\mathrm{n}=25)\end{array}$ & P value \\
\hline Postoperative complications & $3(20.0 \%)$ & $6(24.0 \%)$ & 0.249 \\
Intraabdominal complications & & & \\
Fluid collection/abscess & $1(6.7 \%)$ & $2(8.0 \%)$ \\
Stricture & 0 & 0 \\
Leakage & 0 & $1(4.0 \%)$ \\
Intestinal obstruction/ileus & $1(6.7 \%)$ & $2(8.0 \%)$ \\
$\begin{array}{l}\text { Wound complications } \\
\text { Medical complications }\end{array}$ & $1(6.7 \%)$ & $2(8.0 \%)$ \\
Mortality & 0 & 0 \\
\hline${ }^{\dagger}$, continuous suture technique using knotless absorbable \\
barbed sutures; ${ }^{\ddagger}$, interrupted simple sutures using absorbable \\
braided sutures.
\end{tabular}

included in this study. The baseline characteristics of the participants are summarized in Table 1. In both groups, perforation was more frequently due to duodenal ulcer than gastric ulcer (group A; $73.3 \%$ vs. $26.7 \%$, group B; $76.0 \%$ vs. $24.0 \%$ ). There were no significant differences in patient demographics between the two groups.

Table 2 shows the surgical results of laparoscopic primary repair and omentopexy. The mean operative time for group A was significantly shorter than that for group B $(84.4 \pm 39.8$ vs. $104.2 \pm 49.4 \mathrm{~min}, \mathrm{P}<0.001)$. The mean postoperative stay was similar in both groups $(8.5 \pm 6.4$ vs. $8.7 \pm 5.2$ day). Moreover, size of perforation site, days of drainage, day of diet resumption were not significantly different between the two groups.

The surgical morbidity rate $(20.0 \%$ vs. $24.0 \%, \mathrm{P}=0.249)$ was not different between groups A and B. Although intraabdominal complications occurred in both groups (2 and 5 events in groups A and B, respectively), all events were managed with conservative treatment without reoperation. Neither late complications nor mortality occurred in either group (Table 3).

Finally, we performed a video review in eight patients in group A to analyze detailed operation time (Figure 2). The mean operation time spent for laparoscopic sutures and omentopexy was 22.7 minutes.

\section{Discussion}

Minimally invasive surgical approaches in abdominal 


\section{Page 4 of 7}

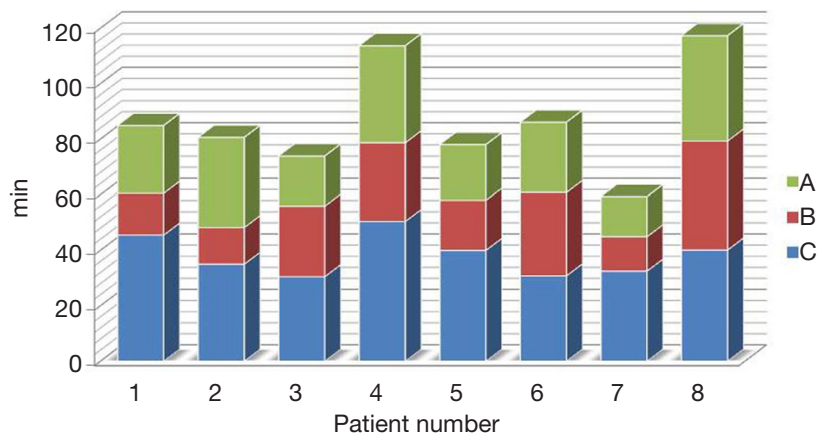

Figure 2 The timeline of duet laparoscopic repair of perforated peptic ulcer based on the video review of eight patients in group A. (A) Abdominal approach and identification of the perforation site (25.9 $\mathrm{min})$, (B) primary repair and omentopexy (22.7 $\mathrm{min}),(\mathrm{C})$ irrigation, drainage, and wound closure (37.8 $\mathrm{min})$.

surgery have been gradually replacing conventional open surgery. Laparoscopic surgery, a representative minimally invasive surgery, has become a standard approach in several elective operations $(16,17)$. In abdominal emergencies, moreover, laparoscopic surgery was shown to be associated with favorable feasibility and safety $(18,19)$ and was used for the treatment of PPU. In fact, PPU is an ideal situation to utilize a laparoscopic approach because of its simplicity. Laparoscopy allows easy identification of the perforation site, primary repair, and peritoneal lavage, comparable to open surgery. Although prospective randomized controlled trials are not possible due to the nature of emergency surgery, several retrospective studies found that there were no significant differences in outcomes between laparoscopic and open approaches for PPU $(1,5,20)$. Thus, in current practice, laparoscopic primary repair and omentopexy are considered as standard treatment for PPU.

Reduced-port laparoscopic surgery has recently become an attractive option for abdominal surgeries due to economical and cosmetic advantages $(12,21)$. Among the several underlying reasons for the appeal of this approach in surgery, the main factor is that technical skills of surgeons can be advanced through video review systems and programs available for practicing the techniques. Popularization of three-dimensional scopes, development of automatic linear staplers, and new suture materials are other important factors. Therefore, increasingly popular reducedport surgery is often preferred for the benefit of the patient and the surgeon's sense of accomplishment. Conversely, this approach is inevitable in certain situations due to the lack of manpower.

\section{Kim et al. Laparoscopic repair with knotless barbed sutures}

The main cause underlying the lack of manpower is the decrease in the number of surgical residents in general surgery programs. During the last decade, candidates comprised less than $70 \%$ of the quota for general surgery. In Korea, except for certain high-volume centers in metropolitan areas, majority of the hospitals have difficulties in procuring surgical residents, which can be explained by several reasons. First, young physicians avoid selecting specialties which are expected to lead to poor quality of life during their residency period and opt for specialties that are relatively comfortable and profitable. Unfortunately, surgery as a specialty is physically and mentally challenging due to the intense hard work required. Second, legal issues are also associated with the lack of manpower. Korea limited the working hours of residents to no more than 80 hours per week in December 2017 (22). Moreover, The Korean Surgical Society announced that the duration of resident training was shortened from four to three years, which was implemented for the first-year residents in 2019. These systemic changes are accelerating the lack of manpower, especially at hospitals in the province.

How can we treat the emergency patients in such circumstances? As the position of junior surgeon, we hypothesized that PPU, one of the most common causes for abdominal surgical emergencies, could be performed safely without a first assistant using reduced-arm duet laparoscopic surgery including only one operator and a scopist. We found that duet laparoscopic repair might be considered as an option for the treatment of PPU. Importantly, there were no differences in operative outcomes or postoperative complications between the two groups; furthermore, the mean operative time was significantly shorter in group A than in group B. Altogether, these findings indicated that duet laparoscopic repair was a feasible procedure that was comparable to conventional laparoscopic repair of PPU.

Among the many factors that enabled duet surgery for PPU repair, the most important is the development of new suture materials. Recently, knotless barbed sutures have been widely accepted in various operation fields. Although knotless barbed sutures have some disadvantages such as high price, impossibility of reverting the suture, and safety issues $(23,24)$, this material has been successfully introduced to general surgery. For laparoscopic bowel suturing, reports of clinical experience have demonstrated consistent decreases in procedure time and comparable complication rates compared to conventional methods $(25,26)$. Knotless barbed sutures have evenly spaced barbs throughout the strand, which provides even distribution 
of tension along the sutured line. This evenly distributed tension can provide good blood supply to the anastomosis site. Additionally, the welded loop design anchors the device at the beginning of the incision line, eliminating the need to tie a knot (13). Surgeons can perform laparoscopic suture alone without much strain using knotless barbed sutures, which can improve sutures in laparoscopy and save time because of easy utilization. In the present study, the duration of laparoscopic suture was shorter compared with other procedures (Figure 2). Kim et al. (14) also reported that the time taken to apply sutures for PPU repair was significantly shorter when using knotless absorbable barbed sutures compared with conventional interrupted sutures.

The development of other surgical techniques and instruments contributed the feasibility of duet laparoscopic surgery for the treatment of patients with PPU. However, our findings do not imply that duet laparoscopic surgery should be the standard procedure as a superior alternative to conventional laparoscopic repair. Instead, we propose this approach as an alternative approach in cases of insufficient manpower, as safety and accuracy should be the primary goals of surgery, which are especially important for abdominal emergencies with high risk of mortality. It is later problems such as pain control and size of wound. Performing surgery with assistants and a secured view is better. The goal of the current study was not to evaluate duet surgery as a replacement but to assess its utility as an alternative for the care of emergency patients in hospitals suffering from lack of manpower.

The current study has several limitations. This retrospective study might have been biased due to unrecognized factors, the main of which is variations in the operators, assistants, and surgical instruments among the surgeries. For patients in group B, surgeries were performed by seven surgeons who were subspecialized in certain surgical fields including breast, colorectal, hepatobiliary, gastrointestinal, and pediatric surgery. However, two surgeons who specialized in gastrointestinal surgery performed all of the operations on patients in group A, which could have affected the significantly shorter operation time. Moreover, three-dimensional scope was used to significantly reduce the operation time for half of the patients (6/12) in group A. As the surgeries were emergent, the same scopist was not available for all operations. A second limitation was the lack of video recordings for patients in group $\mathrm{B}$, that prevented the comparison of the laparoscopic suture times between groups A and B. Video recording of emergency surgeries for PPU repair is a real difficulty, especially for surgeons from other specialties. Finally, the present study had a limited sample size to support the conclusions. Further, well-designed studies are necessary to confirm the validity of duet laparoscopic surgery for the treatment of patients with PPU.

Adapting and improving a new surgical technique is important for both surgeons and patients. These efforts should be continued, albeit always based on scientific rationale with safety of the patient as the most important factor during surgery. The findings of the current study, albeit performed retrospectively at a single institution, suggested that duet laparoscopic repair of PPU with knotless barbed sutures might be considered as an alternative option, especially in hospitals lacking manpower.

\section{Acknowledgments}

Funding: The present research was conducted by the research fund of Dankook University in 2019.

\section{Footnote}

Reporting Checklist: The authors have completed the STROBE reporting checklist. Available at http://dx.doi. org/10.21037/atm-20-3496

Data Sharing Statement: Available at http://dx.doi. org/10.21037/atm-20-3496

Peer Review File: Available at http://dx.doi.org/10.21037/ atm-20-3496

Conflicts of Interest: All authors have completed the ICMJE uniform disclosure form (available at http://dx.doi. org/10.21037/atm-20-3496). The authors have no conflicts of interest to declare.

Ethical Statement: The authors are accountable for all aspects of the work in ensuring that questions related to the accuracy or integrity of any part of the work are appropriately investigated and resolved. This study was performed according to the Helsinki Declaration (as revised in 2013). The institutional review board (IRB) of the Dankook University Hospital approved the protocol (IRB number; 201811021), and written informed consent was waived by the IRB.

Open Access Statement: This is an Open Access article 
distributed in accordance with the Creative Commons Attribution-NonCommercial-NoDerivs 4.0 International License (CC BY-NC-ND 4.0), which permits the noncommercial replication and distribution of the article with the strict proviso that no changes or edits are made and the original work is properly cited (including links to both the formal publication through the relevant DOI and the license). See: https://creativecommons.org/licenses/by-nc-nd/4.0/.

\section{References}

1. Byrge N, Barton RG, Enniss TM, et al. Laparoscopic versus open repair of perforated gastroduodenal ulcer: A National Surgical Quality Improvement Program analysis. Am J Surg 2013;206:957-62.

2. Thorsen K, Søreide JA, Søreide K. Scoring systems for outcome prediction in patients with perforated peptic ulcer. Scand J Trauma Resusc Emerg Med 2013;21:25.

3. Lagoo S, Mc Mahon RL, Kalkharu M, et al. The sixth decision regarding perforated duodenal ulcer. JSLS 2002;6:359-68.

4. Wang YR, Richter JE, Dempsey DT. Trends and outcomes of hospitalizations for peptic ulcer disease in the United States, 1993 to 2006. Ann Surg 2010;251:51-8.

5. Vaira D, Menegatti M, Miglioli M. What is the role of Helicobacter pylori in complicated ulcer disease? Gastroenterology 1997;113:S78-84.

6. Boey J, Choi SK, Poon A, et al. Risk stratification in perforated duodenal ulcers. A prospective validation of predictive factors. Ann Surg 1987;205:22-6.

7. Buck DL, Vester-Andersen M, Moller MH. Surgical delay is a critical determinant of survival in perforated peptic ulcer. Br J Surg 2013;100:1045-9.

8. Kim HH, Han SU, Kim MC, et al. Long-term results of laparoscopic gastrectomy for gastric cancer: a large-scale case control and case-matched Korean multicenter study. J Clin Oncol 2014;32:627-33.

9. Kim YW, Baik YH, Yun YH, et al. Improved quality of life outcomes after laparoscopy assisted distal gastrectomy for early gastric cancer: results of a prospective randomized clinical trial. Ann Surg 2008;248:721-7.

10. Kim SM, Ha MH, Seo JE, et al. Comparison of reduced port totally laparoscopic distal gastrectomy (duet TLDG) and conventional laparoscopic-assisted distal gastrectomy. Ann Surg Oncol 2015;22:2567-72.

11. Ahn SH, Son SY, Lee CM, et al. Intracorporeal uncut Roux-en-Y gastrojejunostomy reconstruction in pure single-incision laparoscopic distal gastrectomy for early gastric cancer: unaided stapling closure. J Am Coll Surg 2014;218:e17-21.

12. Jeong O, Park YK, Ryu SY. Early experience of duet laparoscopic distal gastrectomy (duet-LDG) using three abdominal ports for gastric carcinoma: surgical technique and comparison with conventional laparoscopic distal gastrectomy. Surg Endosc 2016;30:3559-66.

13. Nemecek E, Negrin L, Beran C, et al. The application of the V-Loc closure device for gastrointestinal sutures: a preliminary study. Surg Endosc 2013;27:3830-4.

14. Kim TH, Park JH, Jeong SH, et al. Feasibility of a novel laparoscopic technique with unidirectional knotless barbed sutures for the primary closure of duodenal ulcer perforation. Surg Endosc 2018;32:3667-74.

15. Laforgia R, Balducci G, Carbotta G, et al. Laparoscopic and open surgical treatment in gastroduodenal perforations: our experience. Surg Laparosc Endosc Percutan Tech 2017;27:113-5.

16. Kim HH, Han SU, Kim MC, et al. Long-term results of laparoscopic gastrectomy for gastric cancer: a large-scale case control and case-matched Korean multicenter study. J Clin Oncol 2014;32:627-33.

17. Kim YW, Baik YH, Yun YH, et al. Improved quality of life outcomes after laparoscopy assisted distal gastrectomy for early gastric cancer: results of a prospective randomized clinical trial. Ann Surg 2008;248:721-7.

18. Sauerland S, Agresta F, Bergamaschi R, et al. Laparoscopy for abdominal emergencies: evidence-based guidelines of the European Association for Endoscopic Surgery. Surg Endosc 2006;20:14-29.

19. Druart ML, Van Hee R, Etienne J, et al. Laparoscopic repair of perforated duodenal ulcer. A prospective multicenter clinical trial. Surg Endosc 1997;11:1017-20.

20. Mirabella A, Fiorentini T, Tutino R, et al. Laparoscopy is an available alternative to open surgery in the treatment of perforated peptic ulcers: a retrospective multicenter study. BMC Surg 2018;18:78.

21. Romanelli JR, Earle DB. Single-port laparoscopic surgery: an overview. Surg Endosc 2009;23:1419-27.

22. Kim DJ, Kim SG. Comparative study of the operative experience of surgical residents before and after 80-hour work week restrictions. Ann Surg Treat Res 2018;95:233-9.

23. Jang SH, Jung YK, Choi SJ, et al. Postoperative mechanical small bowel obstruction induced by V-Loc barbed absorbable suture after laparoscopic distal gastrectomy. Ann Surg Treat Res 2017;92:380-2.

24. Sakata S, Kabir S, Petersen D, et al. Are we burying our heads in the sand? Preventing small bowel obstruction 
from the $\mathrm{V}$-loc(R) suture in laparoscopic ventral rectopexy. Colorectal Dis 2015;17:O180-3.

25. Tyner RP, Clifton GT, Fenton SJ. Hand-sewn gastrojejunostomy using knotless unidirectional barbed absorbable suture during laparoscopic gastric bypass. Surg
Endosc 2013;27:1360-6.

26. De Blasi V, Facy O, Goergen M, et al. Barbed versus usual suture for closure of the gastrojejunal anastomosis in laparoscopic gastric bypass: a comparative trial. Obes Surg 2013;23:60-3.

Cite this article as: Kim DW, Song S, Jee YS. Duet laparoscopic repair with knotless barbed sutures for treatment of perforated peptic ulcer: reality in general surgery with lacking of manpower. Ann Transl Med 2021;9(4):311. doi: 10.21037/atm-20-3496 